Article

\title{
Mechanical Properties and Chemical Resistance of New Composites for Oil Pump Impellers
}

\author{
Dilyus I. Chukov ${ }^{1, *(1)}$, Andrey A. Stepashkin ${ }^{1}$, Alexey I. Salimon ${ }^{1}$, Sergey D. Kaloshkin ${ }^{1}$ \\ and Ivan S. Pyatov ${ }^{2}$ \\ 1 Center for composite materials, National University of Science and Technology "MISIS", \\ 119049 Moscow, Russia; a.stepashkin@misis.ru (A.A.S.); a.salimon@misis.ru (A.I.S.); \\ kaloshkin@misis.ru (S.D.K.) \\ 2 "REAM-RTI" LLC, 143902 Balashikha, Russia; info@ream-rti.ru \\ * Correspondence: dil_chukov@mail.ru; Tel.: +7-903-269-03-43
}

Received: 11 April 2018; Accepted: 2 May 2018; Published: 9 May 2018

check for updates

Featured Application: The composites discussed herein provide a competitive alternative to composites based on high-performance thermoplastics in terms of cost and complex shaping in pump parts manufacturing.

\begin{abstract}
In this paper, a new class of high-performance composites and a method of their production based on the carbonization of an elastomeric matrix are proposed. The use of elastomeric matrix makes it possible to manufacture products with complex shapes, while the subsequent carbonization can significantly improve their properties by changing the chemical nature of the elastomeric matrix. Such an approach can reduce the products' machining cost, especially for composites reinforced with super hard fillers such as silicon carbide at high filling degrees. Low-temperature carbonization makes it possible to obtain composites with mechanical behavior similar to that of ceramics. In contrast to classical elastomeric materials, the nitrile butadiene rubber (NBR)-based compounds were highly filled (300 parts per hundred rubber-PHR) with different carbon fillers and silicon carbide; then cured and carbonized at low-temperature $360^{\circ} \mathrm{C}$ with the carbonization cycle of $12 \mathrm{~h}$. The feasibility of the production method was validated through the manufacturing of products with complex shapes-impellers for electric centrifugal pumps. It was found that the carbonized composites have good chemical resistance and low water absorption. The composites have high Shore D hardnesses (93-96), ultimate tensile strengths (62-85 MPa), Young's moduli (17-24 GPa), and compressive strengths (155-181 MPa).
\end{abstract}

Keywords: composite materials; carbon materials; carbonization; nitrile butadiene rubber

\section{Introduction}

Various methods and approaches based on physicochemical treatment of both matrix and fillers materials are used nowadays to obtain high performance composites. The partial or complete carbonization of polymers is an efficient method for obtaining materials with improved properties. One of the most frequently used approaches to produce carbon fibers (CFs) is the carbonization of polyacrylonitrile (PAN). PAN-based fibers have proved to be most suitable precursors for producing high-performance CFs generally because of the high melting point and char yield $[1,2]$. Using PAN-fibers as precursors leads to the development of a thermally stable and extremely oriented molecular structure [3]. In CF manufacturing, PAN-fibers undergo significant changes through a series of thermal processing steps including stabilization, low-temperature carbonization, and high-temperature carbonization [4]. Most PAN-based carbon fibers extensively applied over the 
past two decades have been used in the composite technology. Many other thermoplastic and thermoset polymers such as polymethyl methacrylate [5], poly(vinyl chloride) [6], polylactide [7], polyarylate [8], phenol formaldehyde resin [9] are also subjected to carbonization during the production of carbon materials possessing improved performance properties.

Although elastomers are widely used in engineering, the elastomeric matrix cannot yield materials with high mechanical properties. To the best of our knowledge, there are no reports on successful production of carbonized rubber-based materials. One reason why is there has been no research into this issue is because rubbers are not prone to carbonization or do not have a satisfactory set of properties after carbonization. We recently proposed a method for the production of carbonized NBR-based composites [10,11]. This method consists of three main stages, including the preparation of highly filled elastomeric compounds using a rubber mixing mill, vulcanization, and low-temperature carbonization. The advantage of the proposed approach to composite materials production is the use of industrial and well-developed technologies for molding rubber products, which can solve the problem of machining products. The proposed approach can yield products with desired shapes and sizes at the preliminary stage of the materials' production by vulcanizing highly filled elastomeric compounds that are subsequently subjected to low-temperature carbonization. The main difference between the low-temperature carbonization and the traditional one is the incompleteness of the thermal destruction and cyclization of the elastomeric matrix as well as the formation of the material properties due to the predominance of consolidation processes over the thermal destruction during heating. The choice of carbonation conditions for the NBR matrix composites was based on well-studied processes and approaches used in the production of carbon fibers from PAN. As fillers, we used CFs, graphite, carbon black, and nanotubes, which are often used as fillers and can significantly improve properties of composites [12-15]. The use of carbon fillers in combination with low-temperature carbonization allowed us to obtain materials with high tensile, compressive, and flexural strengths, relatively high impact toughnesses, and high operating temperatures. In this paper, we present the results of our study of the chemical resistance and other performance properties required in industrial applications of the carbonized materials and the products manufactured by the proposed approach.

\section{Materials and Methods}

The highly filled elastomeric compounds based on nitrile-butadiene rubber (BNKS-18AMN, JSC "Krasnoyarsk Synthetic Rubbers Plant", Krasnoyarsk, Russia) were obtained using a rubber-mixing mill. For all the compounds, the degree of filling was 300 parts per hundred rubber (PHR). As fillers, SiC (64C, LLC "NPK Ermakhim”, Moscow, Russia), chopped CFs (UKN-5000, CJSC "Holding Company "Composite", Moscow, Russia), graphite (GMZ, LC "Moscow Electrode Plant", Moscow, Russia), shungite fillers (Carbosil T-20, JSC “Ecochimmach", Bui, Russia), carbon black (P234, LLC "Southern Chemical Company", Krasnodar, Russia), and CNTs (Taunit, LLC "NanoTechCenter" , Tambov, Russia) were used. The compositions of the composites were as follows: T2-carbosil/CB (250/50 PHR); T2-2-carbosil/CB/CF (200/50/50 PHR); SiC-1-graphite/SiC/CF/CB/CNTs (190/60/40/9/1 PHR); SiC-4-SiC/graphite/CF/ CB/CNTs (200/50/40/9/1 PHR). The mixing cycle was carried out as follows: the components of the composite were introduced into the elastomeric mixture alternately, in a sequence of increasing the particle sizes (i.e., nanotubes $\rightarrow$ schungite $\rightarrow \mathrm{SiC} \rightarrow$ graphite $\rightarrow$ carbon fibers). The carbon fibers were introduced in the final stage to keep their maximum length in the composites, with the mechanical properties of the obtained materials being mainly determined by the length of the carbon fibers. Vulcanization of the elastomeric compounds was carried out at $170{ }^{\circ} \mathrm{C}$ for $10 \mathrm{~min}$ under a pressure of $3.5 \mathrm{MPa}$. Carbonization of the composites was carried out at $360^{\circ} \mathrm{C}$ with a specific heating-and-hold run that lasted $12 \mathrm{~h}$. Principal technology was previously proposed and implemented by LLC "REAM-RTI" under the name "Karbul" for the production of products for submersible oilfield equipment. Figure 1 shows impellers that were produced using the proposed method. The diameter of the impellers was $65 \mathrm{~mm}$, the diameter of the impellers eye was $18 \mathrm{~mm}$, and the minimum thickness was $2 \mathrm{~mm}$; these impellers were made for oil pumps with the following 
performance properties: the flow rate is $260-370 \mathrm{~m}^{3} /$ day, the total head is $4.5-6.3 \mathrm{~m}$, and the specific speed (metric units) is 1500-1650.
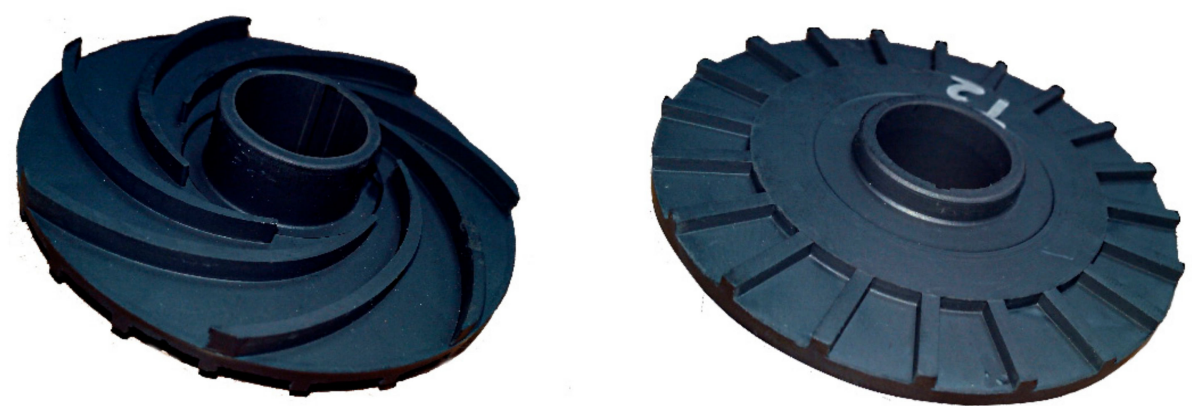

Figure 1. Prototypes of the products (impellers for electric centrifugal pumps) from the carbonized composites (view from both sides).

The microstructure was studied using a TESCAN VEGA 3 scanning electron microscope. The water absorption was investigated according to ISO 62:2008, the effects of immersion in liquid chemicals were investigated according to ISO 175:2010 using nitric $\left(\mathrm{HNO}_{3}, 40 \%\right)$, sulfuric $\left(\mathrm{H}_{2} \mathrm{SO}_{4}\right.$, $30 \%)$, hydrochloric $(\mathrm{HCl}, 37 \%)$ acids and sodium hydroxide $(\mathrm{NaOH}, 40 \%)$. The mechanical properties were studied using Zwick/Roell Z020 machine according to ISO 527 and ISO 604.

\section{Results and Discussion}

It is well known that the structure of composites has a significant effect on their properties: the interaction between the matrix and the fillers and the fillers distribution determine the mechanical, tribological, and thermal behavior of the composites. The method for producing composites should provide good adhesion between the components and the uniform filler distribution. The microstructure of the carbonized composites is shown in Figure 2.
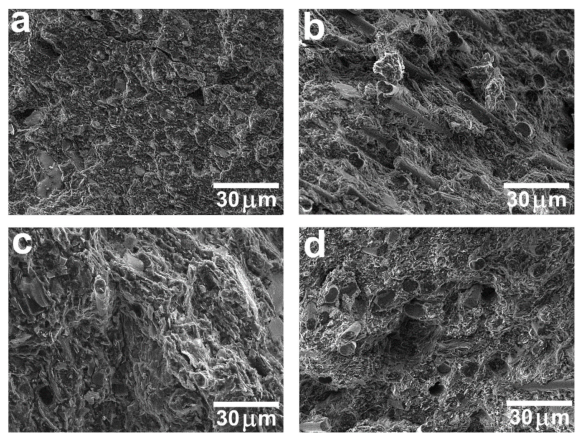

Figure 2. The microstructure of the carbonized composites: (a) T2; (b) T2-2; (c) SiC-1; (d) SiC-4 compounds.

It was found that the CFs during the mixing are crushed, and their length in the composites was in a range of 150-300 $\mu \mathrm{m}$, regardless of the initial length. At CFs content up to 50 PHR, a uniform distribution of the fibers is provided, and a good interfacial interaction between the rubber and the $\mathrm{CFs}$ is observed. It can also be seen that mixing uniformly distributes the fillers in the rubber matrix. Frequently, high filler content levels result in a decrease in the properties caused by an increase in the tendency of the fillers to aggregate and form larger particles [16]. This causes a reduction of the aspect ratio of the filler and of the interaction surface area between the matrix and the filler. In our case, for the manufactured composites, a uniform filler distribution was achieved, which yielded materials with a homogeneous structure and high-performance properties. 
A critical aspect of using the composite materials is their performance in moisture and chemical environments. The absorbed water usually affects mechanical performance and long-term durability of high-performance composites $[17,18]$. The water absorption of the carbonized composites after 70 days is shown in Figure 3a.
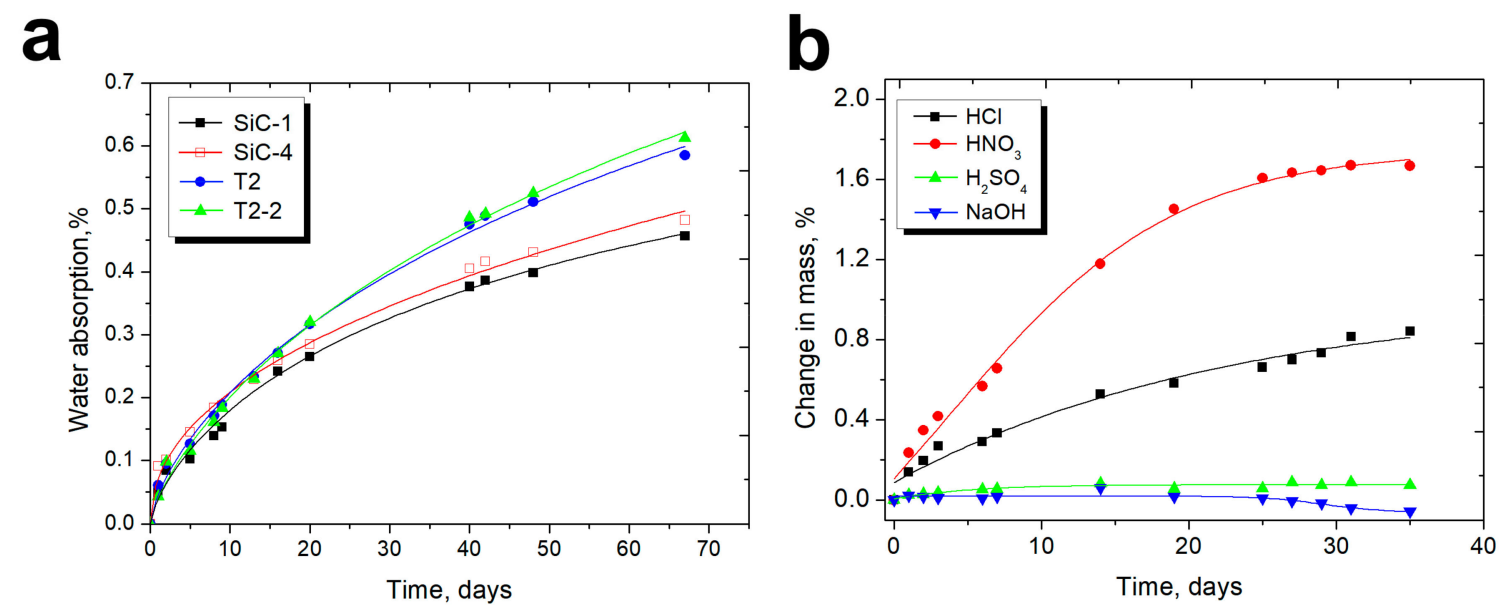

Figure 3. Water absorption (a) of the carbonized composites and (b) change in mass of SiC-1 compounds exposed to liquid chemicals.

It was found that the water absorption values lie quite close to each other $(0.45-0.61 \mathrm{wt} \%)$. Some difference can be related to the nature of the fillers; so the moisture permeability of SiC-reinforced composites is lower than that of for T2 and T2-2 SiC-free compounds that do not contain SiC. Therefore, it can be concluded that the SiC-reinforced composites have a smaller volume of open porosity. The contact angle (CA), which characterizes the hydrophobicity important for the performance of pump parts, decreases from $110-106^{\circ}$ for the vulcanized composites to $62-70^{\circ}$ for the carbonized ones (Table 1). This is due to the presence of a large amount of oxygen-containing functional groups on the surface of the materials after carbonization. Moreover, the SiC-reinforced composites have smaller values of $\mathrm{CA}$, because $\mathrm{SiC}$ itself has a more hydrophilic nature than that of carbon.

Table 1. Change in mass of carbonized composites after exposure to various liquids after 35 days.

\begin{tabular}{ccccccc}
\hline \multirow{2}{*}{ Designation } & \multicolumn{4}{c}{ Change in Mass, \% } & \multicolumn{2}{c}{ Contact Angle, Deg } \\
\cline { 2 - 7 } & $\mathbf{H}_{\mathbf{2}} \mathbf{O}$ & $\mathbf{H N O}_{\mathbf{3}}$ & $\mathbf{H}_{\mathbf{2}} \mathbf{S O}_{\mathbf{4}}$ & $\mathbf{H C l}$ & $\mathbf{N a O H}$ & $\mathbf{H}_{\mathbf{2}} \mathbf{O}$ \\
\hline $\mathrm{T} 2$ & +0.58 & +4.73 & +0.73 & +2.44 & -0.08 & $69.7 \pm 0.5$ \\
$\mathrm{~T} 2-2$ & +0.61 & +4.42 & +0.56 & +2.24 & -0.11 & $70.0 \pm 0.3$ \\
$\mathrm{SiC}-1$ & +0.45 & +1.63 & +0.07 & +0.86 & -0.05 & $64.5 \pm 0.8$ \\
$\mathrm{SiC}-4$ & +0.48 & +1.50 & +0.12 & +0.83 & -0.15 & $62.6 \pm 1.1$ \\
\hline
\end{tabular}

Since the NBR and its composites are not resistant to oxidizing chemicals [19], the effects of immersion in liquid chemicals are also a critical performance aspect of using the obtained composite materials. The change in mass of the SiC- 1 composites exposed to various liquids during 35 days is shown in Figure 3b. These curves show time dependences of the composite's mass changes; they are typical for all composites and have similar behavior. Table 1 summarizes the data on a change in mass after exposure to various liquids after 35 days. It was found that, for $\mathrm{T} 2$ and $\mathrm{T} 2-2$, the change in mass after exposure to liquid chemicals, as well as after exposure to water, was higher than that of for $\mathrm{SiC}-1$ and $\mathrm{SiC}-4$ due to lower porosity of the latter. It was found that the noticeable changes are observed for samples exposed in $\mathrm{HNO}_{3}$. For all compositions, a noticeable increase in mass occurs, indicating that $\mathrm{HNO}_{3}$ has a rather high permeability. The analysis of the effect of $\mathrm{HCl}$ showed a similar tendency 
for all samples, and a gradual increase in mass was observed; however, in this case, the change in mass was much lower. Sulfuric acid only leads to a slight increase in mass $(0.5-0.7 \%)$, which is close to the values of water absorption. The exposure to $\mathrm{NaOH}$ was accompanied by some loss of mass of the composites (about $-0.15 \%$ ), which is caused by partial dissolution of silicon-containing fillers, both schungite and $\mathrm{SiC}$, due to easy dissolution of the surface $\mathrm{SiO}_{2}$ layer in alkalis. It is known that corrosion of the $\mathrm{SiC}$ - and silicon-containing ceramics in the $\mathrm{HCl}$ and $\mathrm{H}_{2} \mathrm{NO}_{3}$ solutions is much weaker than that of in the $\mathrm{NaOH}$ solution, due to the easy dissolution of the $\mathrm{SiO}_{2}$ layer on the ceramic surface into the alkaline solution [20]. Taking into account the simultaneous water absorption that masks the loss of mass, we can conclude that the real loss of mass does not exceed $0.8 \%$. No visible changes in the structure, the sizes, and the colors were noticed, indicating that the composites are highly resistant to any attacks of the most common chemicals.

The mechanical properties of the composites are shown in Table 2. The values of compressive strengths are close and lie in a range of 155-180 MPa for all the composites. It was found that an increase in CF content and the replacement of graphite by shungite fillers, whose average particle size is smaller (T2 and SiC-1), increases Young's modulus. However, in our previous work, it was shown that an increase in $\mathrm{SiC}$ content results in a decrease in the thermal conductivity of the composites due to a decrease in graphite content [11]. Carbon black and CNTs are active fillers that increase mechanical properties, but high filler content significantly reduces the plasticity of the elastomeric compounds, and the fillers tend to form agglomerates at high filling degrees. With an increase in $\mathrm{SiC}$ and a simultaneous decrease in graphite content, the tensile strength and Young's modulus of the composites increase from 62.9 MPa and 17.6 GPa (SiC-1) to 81.2 MPa and 21.3 GPa (SiC-4), respectively. Elongation at break is almost the same for all compositions and lies in a range of $0.4-0.5 \%$. The mechanical properties of the composites are comparable with carbon-carbon composites reinforced with short CFs [21]. It should be noted that carbonized NBR with no fillers shows poor mechanical properties (tensile strength is about $2.7 \mathrm{MPa}$, Young's modulus is about $1.8 \mathrm{GPa}$, and elongation at break is about $0.4 \%$ ). Therefore, the fillers used as well as high filling degrees (up to 300 PHR) mainly determine mechanical properties of the carbonized composites. Carbonization of the unfilled rubber is accompanied by significant shape changes and distortions of the experimental samples. High filling degrees of the rubber with all fillers used reduce form alterations of the produced composites during carbonization.

Table 2. The performance properties of carbonized composites.

\begin{tabular}{cccccc}
\hline \multirow{2}{*}{ Designation } & $\begin{array}{c}\text { Hardness } \\
\text { Shore D }\end{array}$ & $\begin{array}{c}\text { Ultimate } \\
\text { Strength, MPa }\end{array}$ & $\begin{array}{c}\text { Young's } \\
\text { Modulus, GPa }\end{array}$ & $\begin{array}{c}\text { Ultimate } \\
\text { Strength, MPa }\end{array}$ & $\begin{array}{c}\text { Young's } \\
\text { Modulus, GPa }\end{array}$ \\
\cline { 3 - 5 } & $95 \pm 1$ & $155.8 \pm 6.6$ & $9.56 \pm 0.14$ & $69.9 \pm 2.8$ & $19.1 \pm 0.7$ \\
$\mathrm{~T} 2$ & $94 \pm 1$ & $180.9 \pm 9.4$ & $14.81 \pm 0.15$ & $84.7 \pm 1.3$ & $24.5 \pm 0.6$ \\
$\mathrm{~T} 2-2$ & $93 \pm 2$ & $166.1 \pm 9.0$ & $7.68 \pm 0.36$ & $62.9 \pm 9.4$ & $17.6 \pm 0.5$ \\
$\mathrm{SiC}-1$ & $96 \pm 1$ & $169.9 \pm 10.1$ & $11.49 \pm 0.27$ & $81.2 \pm 7.7$ & $21.3 \pm 0.6$ \\
$\mathrm{SiC}-4$ & &
\end{tabular}

It is important to note that Young's modulus has an asymmetrical character being almost two times higher at tension than at compression. We believe that this asymmetry is related to specific features of the composite structure, i.e., the presence and spatial distribution of CFs and intrinsic porosity as well as the elastic behavior of a partially carbonized matrix. Strong adhesion of the partially carbonized matrix with CFs implies higher stiffness at tension, whereas the collapsing of pores at compression reduces the stiffness from the basic level of stiffness for the non-porous carbonized matrix.

\section{Conclusions}

We report here the successful manufacturing of new composite materials and products through low-temperature carbonization of highly filled NBR. The use of fillers of various morphologies, 
such as SiC, carbon fibers, graphite, shungite fillers, carbon black, and CNTs, yielded thermally and dimensionally stable composite materials from elastomeric compounds. All used fillers reduce form alteration of the composites at carbonization providing the production of items with the required sizes and shapes. It was shown that good adhesion between fillers and carbonized matrix can yield good strength-elastic properties of the composites, comparable with carbon-carbon composites reinforced with short CFs. The carbonized composites showed good chemical resistance and low water absorption. No visible changes in the structure, the sizes, or the colors during immersion in various liquids were noticed, indicating that the composites are highly resistant to attacks of the most common chemicals. The SiC-reinforced composites have a smaller volume of available porosity and lower liquid permeability than the SiC-free composites. The composites and the developed method provide a competitive alternative to composites based on high-performance thermoplastics in terms of cost and complex shaping in manufacturing parts for pumping equipment.

Author Contributions: D.I.C. performed the experiments and wrote the paper; A.A.S. manufactured the composites and performed the experiments; A.I.S. performed the experiments and analyzed the data; S.D.K. analyzed the data and wrote the paper; I.S.P. conceived and designed the experiments.

Funding: This research was funded by Ministry of Education and Science of Russian Federation grant number 14.578.21.0133, 27 October 2015. Unique identifier of applied scientific researches: RFMEFI57815X0133.

Acknowledgments: This work was supported by Ministry of Education and Science of Russian Federation (RFMEFI57815X0133). The authors thank E. Bazanova for her critical reading and many helpful suggestions.

Conflicts of Interest: The authors declare no conflict of interest. The founding sponsors had no role in the design of the study; in the collection, analyses, or interpretation of data; in the writing of the manuscript; or in the decision to publish the results.

\section{References}

1. Bahl, O.P.; Mathur, R.B. Effect of load on the mechanical properties of carbon fibres from pan precursor. Fibre Sci. Technol. 1979, 12, 31-39. [CrossRef]

2. Bahl, O.P.; Manocha, L.M. Characterization of oxidised pan fibres. Carbon 1974, 12, 417-423. [CrossRef]

3. Rahaman, M.S.A.; Ismail, A.F.; Mustafa, A. A review of heat treatment on polyacrylonitrile fiber. Polym. Degrad. Stab. 2007, 92, 1421-1432. [CrossRef]

4. Ji, M.; Wang, C.; Bai, Y.; Yu, M.; Wang, Y. Structural Evolution of Polyacrylonitrile Precursor Fibers during Preoxidation and Carbonization. Polym. Bull. 2007, 59, 527-536. [CrossRef]

5. Dong, Y.; Gui, Z.; Jiang, S.; Hu, Y.; Zhou, K. Carbonization of Poly (methyl methacrylate) by Incorporating Hydroxyapatite Nanorods during Thermal Degradation. Ind. Eng. Chem. Res. 2011, 50, 10903-10909. [CrossRef]

6. Poerschmann, J.; Weiner, B.; Woszidlo, S.; Koehler, R.; Kopinke, F.-D. Hydrothermal carbonization of poly(vinyl chloride). Chemosphere 2015, 119, 682-689. [CrossRef] [PubMed]

7. Wen, X.; Gong, J.; Yu, H.; Liu, Z.; Wan, D.; Liu, J.; Jiang, Z.; Tang, T. Catalyzing carbonization of poly(L-lactide) by nanosized carbon black combined with $\mathrm{Ni}_{2} \mathrm{O}_{3}$ for improving flame retardancy. J. Mater. Chem. 2012, 22, 19974-19980. [CrossRef]

8. Kawahara, Y.; Otoyama, S.; Yamamoto, K.; Wakizaka, H.; Shinahara, Y.; Hoshiro, H.; Ishibashi, N.; Iwashita, N. Direct Carbonization of High-performance Aromatic Polymers and the Production of Activated Carbon Fibers. J. Text. Sci. Eng. 2015, 5, 1-5. [CrossRef]

9. Laušević, Z.; Marinković, S. Mechanical properties and chemistry of carbonization of Phenol formaldehyde resin. Carbon 1986, 24, 575-580. [CrossRef]

10. Stepashkin, A.A.; Chukov, D.I.; Kaloshkin, S.D.; Pyatov, I.S.; Deniev, M.Y. Carbonised composite materials based on elastomers filled with carbon nanofillers. Micro Nano Lett. 2018. [CrossRef]

11. Stepashkin, A.A.; Chukov, D.I.; Kaloshkin, S.D.; Pyatov, I.S.; Deniev, M.Y. Carbonized elastomer based composites filled with carbon fillers and silicon carbide. Mater. Lett. 2018, 215, 288-291. [CrossRef]

12. Chukov, D.I.; Stepashkin, A.A.; Maksimkin, A.V.; Tcherdyntsev, V.V.; Kaloshkin, S.D.; Kuskov, K.V.; Bugakov, V.I. Investigation of structure, mechanical and tribological properties of short carbon fiber reinforced UHMWPE-matrix composites. Compos. Part B Eng. 2015, 76, 79-88. [CrossRef] 
13. Chukov, D.I.; Stepashkin, A.A.; Tcherdyntsev, V.V.; Kaloshkin, S.D.; Danilov, V.D. Strength and thermophysical properties of composite polymer materials filled with discrete carbon fiber. Inorg. Mater. Appl. Res. 2014, 5, 386-391. [CrossRef]

14. Maksimkin, A.V.; Kharitonov, A.P.; Mostovaya, K.S.; Kaloshkin, S.D.; Gorshenkov, M.V.; Senatov, F.S.; Chukov, D.I.; Tcherdyntsev, V.V. Bulk oriented nanocomposites of ultrahigh molecular weight polyethylene reinforced with fluorinated multiwalled carbon nanotubes with nanofibrillar structure. Compos. Part B Eng. 2016, 94, 292-298. [CrossRef]

15. Stepashkin, A.A.; Chukov, D.I.; Cherdyntsev, V.V.; Kaloshkin, S.D. Surface treatment of carbon fibers-fillers for polymer matrixes. Inorg. Mater. Appl. Res. 2014, 5, 22-27. [CrossRef]

16. Usha Devi, K.S.; Ponnamma, D.; Causin, V.; Maria, H.J.; Thomas, S. Enhanced morphology and mechanical characteristics of clay/styrene butadiene rubber nanocomposites. Appl. Clay Sci. 2015, 114, 568-576. [CrossRef]

17. Pérez-Pacheco, E.; Cauich-Cupul, J.I.; Valadez-González, A.; Herrera-Franco, P.J. Effect of moisture absorption on the mechanical behavior of carbon fiber/epoxy matrix composites. J. Mater. Sci. 2013, 48, 1873-1882. [CrossRef]

18. Do, V.-T.; Nguyen-Tran, H.-D.; Chun, D.-M. Effect of polypropylene on the mechanical properties and water absorption of carbon-fiber-reinforced-polyamide-6/polypropylene composite. Compos. Struct. 2016, 150, 240-245. [CrossRef]

19. Shanks, R.A.; Kong, I. General Purpose Elastomers: Structure, Chemistry, Physics and Performance. In Advances in Elastomers I; Advanced Structured Materials; Springer: Berlin/Heidelberg, Germany, 2013; pp. 11-45. ISBN 978-3-642-20924-6.

20. Andrews, A.; Herrmann, M.; Sephton, M.; Machio, C.; Michaelis, A. Electrochemical corrosion of solid and liquid phase sintered silicon carbide in acidic and alkaline environments. J. Eur. Ceram. Soc. 2007, 27, 2127-2135. [CrossRef]

21. Chichinadze, A.V.; Albagachiev, A.Y.; Kozhemyakina, V.D.; Kokonin, S.S.; Suvorov, A.V.; Kulakov, V.V. Assessment of friction and wear characteristics of domestic friction composite materials in loaded aircraft brakes. J. Frict. Wear 2009, 30, 261-270. [CrossRef] 